\title{
Health related quality of life and its correlates among people with depression attending outpatient department in Ethiopia: a cross sectional study
}

\author{
Seid Shumye*, Zelalem Belayneh(1) and Nebiyu Mengistu
}

\begin{abstract}
Background: Depression is a common mental disorder negatively affects the cognitive, emotion, behavior, functionality and quality of life of people. Poor quality of life results in high rates of relapse, inability to perform occupational and social activities, impaired future outlook, and increases overall health care related costs. However, there is no available evidence regarding the health related quality of people with depression in Ethiopia. Therefore, evaluating the quality of life of people with depression is crucial.
\end{abstract}

Objective: The aim of this study was to assess the health related quality of life and its correlates among people with depression at Amanuel Mental Specialized Hospital, Addis Ababa, Ethiopia.

Methods: An institutional based cross-sectional study was conducted from May ${ }^{1 \text { st }}$ to ${ }^{30 \text { th }}, 2018$. A randomly selected 394 clients with depression were participated in this study. Health related quality of life was measured using world health organization quality of life brief. The collected data were coded and entered to SPSS version 20 for analysis. Step wise multiple linear regression analysis was used to identify the correlates of quality of life and the strength of the correlation was measured by $\beta$ coefficient with $95 \%$ confidence interval.

Results: The mean $( \pm \mathrm{SD})$ scores of quality of life of people with depression were $41.3 \pm 7.5,42.8 \pm 8.2,38.9 \pm 8.9$ and $41.8 \pm 6.5$ for physical, psychological, social and environmental domains, respectively. The Multiple regression analysis showed that age of respondents, age of onset of depression, perceived stigma, living arrangement, social support level and duration of illness were statistically significant predictors of health related quality of life of people with depression in all or at least one domain of quality of life.

Conclusions: This study revealed that nearly half of study participants scored below the mean score in each domain of health related quality of life. This demonstrates a need for improving the quality of life of people with depression through the integration of a positive mental health approach and bio-psychosocial view together with the pharmacological treatments of depression. Moreover, strengthening social support, early identification and treatment of depression and prevention of stigma are also highly recommended to improve the quality of life of people with depression.

Keywords: Quality of life, Depression, Mental illness, Psychosocial support, Mental disorder

\footnotetext{
* Correspondence: seidshumye22@gmail.com

Department of Psychiatry, College of Health and Medical Science, Dilla

University, Dilla, Ethiopia
}

(c) The Author(s). 2019 Open Access This article is distributed under the terms of the Creative Commons Attribution 4.0 International License (http://creativecommons.org/licenses/by/4.0/), which permits unrestricted use, distribution, and reproduction in any medium, provided you give appropriate credit to the original author(s) and the source, provide a link to the Creative Commons license, and indicate if changes were made. The Creative Commons Public Domain Dedication waiver (http://creativecommons.org/publicdomain/zero/1.0/) applies to the data made available in this article, unless otherwise stated. 


\section{Background}

Quality of life (QOL) is defined as "individuals' perceptions of their position in the context of the culture and value systems they live and in relation to their goals, expectations, standards and concerns" [1,2]. It is a broad ranging concept incorporating the persons' physical health, psychological state, level of independence, social relationships, and their relationships to silent features of the environment [2-4]. In recent times, QOL is considered as an important component and prognostic indicator of mental illness and recommended to be integrated in the clinical evaluation and interventions of people with severe mental illness [3, 4].

People with severe mental illness are more vulnerable to have a diminished health related quality of life, and depression takes a higher proportion $[4,5]$. Thus, the nature of symptoms (loss of interest, depressed mood, lack of interest for pleasurable activities, low self esteem, psychomotor retardation and other) and its comorbod illnesses together with the social, occupational and cognitive impairments significantly affect the quality of life of people with depression [6, 7]. The prevalence of depression is estimated to be $11 \%$ and $9.1 \%$ globally and in Ethiopia, respectively $[8,9]$.

Literatures showed the quality of life of people with depression is highly impaired in both the developed and developing nations $[10,11]$. Age of patients, onset of depression, medication non-adherence, comorbod illness, and poor social support, perceived stigma of their depressive status and family history of depression were found to have a statistically significant association with health related quality of life of people with depression [12-15]. The poor quality of life among people with depression again can increase the vulnerability for medical complications such as chronic heart disease, diabetes mellitus and hypertension due to the immunity compromization effects of stress related to poor quality of life $[16,17]$.

Patients with depression and their relatives increasingly expect improvements not only their symptoms, but beyond that improvements of their functioning and quality of life $[18,19]$. There is also a growing consensus that successful treatment of depression should not only target symptom severity, but also impairment in functioning and QOL in leading to restoration of health $[20,21]$. The scope of treatment of people with depression therefore, extends to the patients' subjective feelings of wellbeing, satisfaction, functioning and impairment beyond to the traditional symptoms reductions approaches $[3,21]$.

Recently, innovative and emerging concepts of euthymia are introduceced to incorporate the psychological construct of health-related quality of life to comprehensive state of positive mental health [22]. This is characterized not simply by the absence of symptoms of depression [23], but by the presence of psychological well-being, quality of life, psychological flexibility, resilience, frustration tolerance and resistance to stress [23-25]. Thus, this is the time that clinical psychologists and other professionals working for mental health related activities have to move from the traditional psychopathology-based perspective to a positive clinical approach to significantly diminish the risk of recurrence of affective disorders, and to use innovative assessment and intervention strategies of health related quality of life [26, 27].

Despite of this considerable opportunity and clinical importance of addressing the quality of life of people with depression, professionals still have a considerable focus only on pharmacotherapy for symptomatic reduction and ignore quality of life of patients with depression [26]. This is the single aspect of treating patients with depression commonly practiced, particularly in developing countries including Ethiopia [28]. As a result a collaborative effort is needed to address the quality of life of people with depression through the integration of a bio-psycho social view in the pharmacological treatment approaches of depression [17, 27].

In Ethiopia, there is no available evidence reporting about the health related quality of life of people with depression, and little is done regarding the positive mental health approach and psychological construct of people with severe mental illness. Therefore, the current study was aimed to fill this gap by assessing the health related quality of life and its predictors among people with depression in Ethiopia. The findings of this study can be important for clinicians, social workers, psychologist, planners, decision makers and mangers. Furthermore, it can be used as baseline information for further studies.

\section{Methods \\ Study design and period}

This was an institutional based cross sectional study conducted from May ${ }^{\text {st to } 30 \text { th }}, 2018$.

\section{Study setting and participants}

The study was conducted at Amanuel Mental Specialized Hospital (AMSH). AMSH is the first hospital started mental health service in Ethiopia since its establishment at 1930 [28]. Currently, AMSH is the only specialized psychiatric hospital in the country serving for people from the nine regions and two city administrations of the country. The hospital provides service for people with psychiatric, neurological, substance and psychosocial problems in both outpatient and inpatient cares. The hospital has 259 beds for people with severe mental illness and emergency mental health conditions to be treated at inpatient services. AMSH hospital also 
has 18 different and separate ODPs serving for 7, 442 monthly estimated individuals with different diagnostic case teams (psychotic, mood, forensic, neurologic, substance, geriatric, NPS). Depression is the first rank based on the number of clients estimated to be served by the hospital every month. The diagnostic level of clients is confirmed by senior psychiatrists of AMSH at the first visit and their clinic condition is also evaluated during the follow up visit. The next follow up visit of clients is scheduled first and documented in the registration book of the hospital. Clients with age above or equal to 18 years, having follow-up visit for at leat 6 months, and having full insight regarding their illness and importance of their treatment were considered as eligible candidate to participate in the interview.

\section{Sampling and data collection techniques}

The minimum number of samples required for the study was calculated by using single population mean formula with assumptions of $1.96 \mathrm{Z}$ value at $(\infty=0.05), 9.65$ standard deviation of the mean quality of life score from a study in Nigeria [10] and margin of error of 1. By considering a $10 \%$ non-response rate, the total sample size was 394.

Prior to the actual data collection, 2114 individuals with depression were expected to visit the hospital from May ${ }^{1 \text { st to } 30 \text { th }}$ according to the schedule documented in the registration book of the hospital. Then, a sampling interval $(\mathrm{K})$ was calculated by diving the total number of depressed patients expected to come to AMSH during the data collection time to the calculated sample size $(\mathrm{K}=2114 / 394=5.37\}$. Then, eligible clients were selected for every six ${ }^{\text {th }}$ intervals according to the order of their follow up evaluation until the calculated sample size (394) was addressed.

The interview was conducted at a separate and private interviewing room adjusted for this purpose around the waiting hall of the hospital. The data collection facilitators sent eligible respondents to the prepared interviewing room and data collectors conducted the interview after obtain written consent. Six data collectors (BSc level psychiatric nurses) and two supervisors (MSc level mental health professional) were participated in the data collection after attending 2 days of training regarding the contents of questionnaire and data collection procedures. Finally, a total of 394 client invited to participate in the interview and 387 (98\%) completed the interview properly.

\section{Data collection instruments}

An interviewer administered questionnaire was used for the data collection. The questionnaire had different domains, including socio-demographic profile, world health organization quality of life brief (WHOQOL-BRFE),
Oslo Social Support Scale, Morisky Green Levine Medication Adherence Scale, Jacoby Stigma Scale, clinical related characteristics and questions related substance use.

The outcome variable (quality of life) was measured using the WHOQOL-BRFE. The tool had 26 items measuring the physical health, psychological state, social relation, and environment aspects. In the physical health domain of the WHOQOL-BRFE, sleep pattern, working capacities, energy and medications use were assessed. In the psychological domain, we measured the thinking, body image and spiritual aspects where as relationships and sexual relations were addressed with in social domain. Finally, the environmental domain addressed the safety, leisure, finance, home and information aspects. WHOQOL-BRFE is a cross-culturally validated instrument to measure the quality of life, particularly useful when addressing the impact of physical and psychological well-being, but also on several domains beyond health, and had good sensitivity and specificity to assess the quality of life of people at health care settings [29]. We have used the Ethiopian validated Version of WHOQOL-HIV-BREF-Eth with good acceptability and psychometric properties [30]. The Cronbach alpha of WHOQOL-HIV-BREF-Eth was 0.82 in this study. QOL raw scores are transformed in to a range between 0 and 100. Scores are scaled in a positive direction (i.e. higher scores correspond to a better health related quality of life and vice versa [31].

Data for independent variables were also collected using standardized tools. Accordingly, Oslo Social Support Scale was used to measure the social support level of study participants. OSSS-3 has been recommended to be used for epidemiological and population-based surveys. The tool has three questions used to assess the numbers of people so close to be counted during great personal problems, level of interest and concern do people show and the accessibility of practical help from neighbors if needed, respectively. The first question has four response options ranging from 1 (none) to 4 (more than five) while the second and third questions has five options. The sum score of OSSS-3 ranges from 3 to 14 . The higher value of the sum score represents stronger levels of social support and vice versa. Based on the sum score of OSSS-3, the level of social support is also categorized into three levels (poor $=$ " $3-8$ ", moderate $=$ "911 ", strong $=$ "12-14") [32]. The tool has been used in different studies with acceptable sensitivity and specificity. In the current study, OSSS- 3 showed a good internal consistency having a Cronbach alpha of 0.91 .

Morrisky Green Levine Medication Adherence Scale was used to evaluate psychotropic medication adherence level of people with depression. The tool had four different "Yes" or "No" questions scored for 1 and 0 , respectively and individuals with a sum score of four and 
above were considered as having poor medication adherence [33].

Regarding the assessment of perceived stigma, we used the Jacoby Stigma Scale with three item questions to assess the individual's perception of stigma regarding their illness. Each of the three questions had two possible responses and scored 0 for "no" responses and 1 for "yes" responses. The tool had a sum scores ranging from 0 to 3 where a score of 1 and above indicating that the patient is stigmatized [34]. The Jacoby Stigma Scale had a Cronbach alpha of 0.7 in the current study. Current substance was also measured by directly asking the client "Yes" or "No" question whether he/she had used substance in the last 1 month or not.

The questionnaire was originally prepared in English and translated into the local language (Amharic) by senior English language experts who are fluent of the local language, and back translated to English by other persons with similar profession and educational level to check its consistency. The questionnaire was pretested at St. Paul's hospital among 5\% of the calculated sample.

\section{Data analysis and interpretation}

The collected data were checked for its completeness and consistency. Then, the data were entered to EPiDATA version 3.1 and transformed to SPSS version 20 for analysis. First, the correlation of each variable was checked and their correlation with health related quality of life using linear regression. Then, variables with $P$ value of less than 0.25 were entered together to the multiple linear regression analysis. Accordingly, age of clients, sex, age of onset of depression, residency, marital status, perceived stigma, living arrangement, level of social support, substance use and follow up duration were entered to multiple linear regression. In the multiple linear regression analysis, age of respondents, age of onset of depression, perceived stigma, living arrangement, social support level and duration of illness were found as a statistically significant predictors of health related quality of life with $P$-values of less than 0.05 . The strength of the correlation was also measured by $\beta$ coefficient with corresponding 95\% CI.

\section{Results}

\section{Socio-demographic characteristics of respondents}

Out of 394 study participants invited to be participated in the interview, 387 completed the interview properly with a response rate of $98 \%$. The mean standard deviation $( \pm \mathrm{SD})$ age of respondents was $40 \pm 8$ years. More than half, (58.4\%) of respondents were males, and $80.6 \%$ reside in urban areas. Majority, (54\%) of participants were married and living together. The mean scores of perceived stigma and social support level were 0.6 and 9.1, respectively (Table 1 ).

\section{Clinical and substance related characteristics}

The median age of onset of depression was 32.0 years. About $67(17.3 \%)$ of participants had an additional comorbid medical illness (Diabetes mellitus (5.1\%), cardiac disease (3.4\%), HIV/AIDS (2.2\%), epilepsy (4.3\%) and others (2.2\%). About $30.3 \%$ of participants were current substance users (Table 2).

\section{Quality of life of people with depression}

Nearly half of the study participants scored below the mean score of the WHOQOL-BRIEF quality of life for all the physical, psychological, social and environmental domains (Table 3).

\section{Correlates of quality of life of people with depression}

The multiple linear regression showed that age of respondents, age of onset of depression, perceived stigma, living arrangement, social support level and duration of illness were found as a statistically significant correlates of health related quality of life for atleast one domain (Table 4).

\section{Discussion}

A new and innovative clinically based evaluation method has been introduced for the assessment of levels of quality of life and psychological distress in patients with depression [22]. Clinicians are supposed to use these newly emerging innovations as a treatment modality of people with depression [23].

However, literatures conclude that the health related quality of life of people with depression is not still well addressed in developing nations including Ethiopia $[17,20,28]$. The findings of the current study also supported this conclusion by showing that nearly half of the study participants scored below the mean score of health related quality of life for all domains. The mean scores of health related quality of life of people with depression in Ethiopia were 41.3, 42.8, 38.9, and 41.8 for physical, psychological, social and environmental domains, respectively. These results are supported by the conclusions of a previous study of Brazil [35], South Africa [36] and Germany [37] which also concluded that health related quality of life of people with depression is very poor. The, nature of symptoms, its comorbod illnesses, impaired self image, social, occupational and cognitive impairments and poor social relationship can play a great role for the lowered quality of life of people with depression $[11,16]$.

However, a study conducted in Pakistan reported that majority of patients with major depressive disorder had a poor QOL with a mean score of $0.26 \pm 0.3$ [7]. This much lower than the mean scores of all domains of health related quality of life reported in the current study. The explanation for the discrepancy of the results might be due to the socio-cultural variations of study 
Table 1 Socio-demographic and psycho-social characteristics of people with depression attending outpatient department at AMSH, Addis Ababa, Ethiopia, $2018(n=387)$

\begin{tabular}{|c|c|c|c|}
\hline Variables & Categories & Frequency & Percentage \\
\hline \multicolumn{4}{|c|}{ Age of respondents (Mean \pm SD) $40 \pm 8$} \\
\hline \multirow[t]{2}{*}{ Sex } & Male & 226 & 58.4 \\
\hline & Female & 161 & 41.6 \\
\hline \multirow[t]{4}{*}{ Ethnicity } & Amhara & 180 & 46.5 \\
\hline & Oromo & 160 & 41.3 \\
\hline & Tigre & 30 & 7.8 \\
\hline & Others $^{a}$ & 17 & 4.4 \\
\hline \multirow[t]{4}{*}{ Religion } & Orthodox & 201 & 51.9 \\
\hline & Muslim & 103 & 26.6 \\
\hline & Protestant & 70 & 18.1 \\
\hline & Others $^{b}$ & 13 & 3.4 \\
\hline \multirow[t]{2}{*}{ Residence } & Urban & 312 & 80.6 \\
\hline & Rural & 75 & 19.4 \\
\hline \multirow[t]{4}{*}{ Marital status } & Single & 209 & 54.0 \\
\hline & Married & 99 & 25.6 \\
\hline & Divorced & 60 & 15.5 \\
\hline & widowed and separated & 19 & 4.9 \\
\hline \multirow[t]{4}{*}{ Educational status } & unable to read and write & 24 & 6.2 \\
\hline & primary education & 110 & 28.4 \\
\hline & secondary education & 73 & 18.9 \\
\hline & Diploma, degree and above & 180 & 46.5 \\
\hline \multirow[t]{4}{*}{ Work status } & Private business & 141 & 36.4 \\
\hline & Jobless & 150 & 38.8 \\
\hline & Employed & 79 & 20.4 \\
\hline & Others $^{c}$ & 17 & 4.3 \\
\hline \multirow[t]{2}{*}{ Living arrangement } & With families & 280 & 72.4 \\
\hline & Alone & 107 & 27.6 \\
\hline \multirow[t]{3}{*}{ Social support } & Strong & 46 & 11.9 \\
\hline & Moderate & 185 & 47.8 \\
\hline & Poor & 156 & 40.3 \\
\hline \multirow[t]{2}{*}{ Perceived stigma } & Yes & 245 & 63.3 \\
\hline & No & 142 & 36.7 \\
\hline
\end{tabular}

Abbreviation: AMSH Amanuel Mental Specialized Hospital

${ }^{\mathrm{a}}$ Gurage, wolayta, Somaliee, Afar, ${ }^{\mathrm{b}}$ Catholic, wakefeta, Hawariyat, ${ }^{\mathrm{C}}$ Farmer, Student

participates and the differences of the screening tools used to measure quality of life [30].

A study from China reported a better mean score of quality of life of outpatients with depression in each domain of health related quality of life [38]. Another cross sectional study in Nigeria among patient with schizophrenia and major affective disorders $(n=108) 2$ weeks after discharge using WHOQOL BREF also showed a better quality of life; at least two-thirds of the subjects were categorized as having better (average) QOL in the physical, psychological and environmental domains of
QOL [39]. This is higher than the finding of the current study regarding the quality of life of people with depression. The discrepancy of these results might be due the better availabilities of strong health care system and shorter duration of the illness in China as compared to Ethiopia [38]. Moreover, this might be due to the large sample size $(n=1,984)$ used, the difference in the socio-demographic characteristics of participants, and also the involvement of only first visit patients as participants in a study conducted [8]. 
Table 2 Clinical related characteristics of people with depression attending outpatient department at AMSH, Addis Ababa, Ethiopia, 2018 $(n=387)$

\begin{tabular}{|c|c|c|c|}
\hline Variables & Categories & Frequency & Percentage \\
\hline \multirow[t]{3}{*}{ Duration of the illness } & Less than 5 years & 219 & 56.6 \\
\hline & $5-10$ years & 100 & 25.8 \\
\hline & Greater than 10 years & 68 & 17.6 \\
\hline \multirow[t]{2}{*}{ Co morbid medical diagnosis } & No & 320 & 82.7 \\
\hline & Yes & 67 & 17.3 \\
\hline \multirow[t]{2}{*}{ Medication adherence } & Adherent & 191 & 49.4 \\
\hline & Non- adherent & 196 & 50.6 \\
\hline \multirow[t]{2}{*}{ Lifetime substance use } & Yes & 321 & 82.9 \\
\hline & No & 66 & 17.1 \\
\hline \multirow[t]{2}{*}{ Current substance use } & Yes & 117 & 30.2 \\
\hline & No & 270 & 69.8 \\
\hline
\end{tabular}

Abbreviation: AMSH Amanuel Mental Specialized Hospital

The current study was also aimed to identify predictors of health related quality of life of people with depression attending outpatient department in Ethiopia. Accordingly, age of respondents had positive correlation with all domains of health related quality of life. As age of respondents increased by 1 year their health related quality of life increases by $0.34,0.37,0.53$, and 0.44 units for physical, psychological, social and environmental domains, respectively. This finding is supported by a study of three European countries [40] i.e. the younger the age of study respondents was a predictor for the poorer the quality of life of their lives. This might be due to the higher tendency to come into a state of acceptance towards themselves and their lives as people become older [36].

Patients with early onset of depression and longer follow up duration (greater than 5 years) had a markedly diminished perception of their health related QOL. This finding is in line with a previous study conducted among outpatients with depression in China [41]. This might be explained by the fact that patients with early onset of depression and longer follow up duration are more likely to have an unfavorable prognosis, higher rates of relapse, chronicity of the illness which increases the likelihood of dissatisfaction with their health related QOL [37].
The physical health domain of QOL was decreased by 2.38 units among study participants with perceived stigma because of their depressive status. This is consistent with the conclusions of other similar studies done in Jordan [14], Czech [42] and Taiwan [11]. This is possibly explained by the lowered self-esteem, social isolation and poor community engagement of people with perceived stigma of their illness with might lead to less satisfaction in their quality of life [42]. The social support level was positively correlated with health related QOL of people with depression. Patients with a stronger social support level had a better health related QOL except the physical domain. This finding is supported by other studies of Argentina [10], Germany [37] and China [41]. This might be due to the fact that people with stronger social support can have a better self image, social relationships, safety and engagement to the community [43]. Furthermore, individuals with stronger social support commonly share moments of both their happiness and distress with someone close to them and get relief from their distress [44].

Similarly, the physical health domain of QOL had reduced by 1.92 units among patients with depression who were living alone as compared to those living with their own families. This is in agreement with a study from Sweden which revealed that living with families was

Table 3 Distributions of quality of life domains among people with depression attending outpatient department at AMSH, Addis Ababa, Ethiopia, $2018(n=387)$

\begin{tabular}{llllll}
\hline Domains & Maximum & Minimum & Mean \pm SD & Scores below mean & $95 \% \mathrm{Cl}$ \\
\hline Physical & 53.57 & 25.00 & $41.3 \pm 7.5$ & $43.9 \%$ & $(40.62,42.14)$ \\
Psychological & 58.33 & 20.83 & $42.8 \pm 8.2$ & $52.7 \%$ & $(41.94,43.61)$ \\
Social & 58.33 & 25.00 & $38.9 . \pm 8.7$ & $44.7 \%$ & $(38.01,39.84)$ \\
Environmental & 53.13 & 28.13 & $41.8 \pm 6.5$ & $51.4 \%$ & $(41.12,42.43)$ \\
\hline
\end{tabular}


Table 4 Multiple linear regression models for physical, psychological, social and environmental domains of quality of life among people with depression attending outpatient department at AMSH, Addis Ababa, Ethiopia, 2018 ( $n=387$ )

\begin{tabular}{|c|c|c|c|c|c|}
\hline \multirow[t]{3}{*}{ Variables } & & \multicolumn{4}{|c|}{ Domains of health related quality of life } \\
\hline & & \multirow{2}{*}{$\begin{array}{l}\text { Physical } \\
\text { B Coefficient with 95\% } \\
\mathrm{Cl}\end{array}$} & \multirow{2}{*}{$\begin{array}{l}\text { Psychological } \\
\text { B Coefficient with 95\% } \\
\text { Cl }\end{array}$} & \multirow{2}{*}{$\begin{array}{l}\text { Social } \\
\text { B Coefficient with 95\% } \\
\text { Cl }\end{array}$} & \multirow{2}{*}{$\begin{array}{l}\text { Environmental } \\
\text { B Coefficient with 95\% } \\
\text { Cl }\end{array}$} \\
\hline & & & & & \\
\hline \multicolumn{2}{|l|}{ Age of participants } & $0.34(0.27,0.42)^{* * *}$ & $0.37(0.27,0.47)^{* * *}$ & $0.53(0.42,0.64)^{* * *}$ & $0.44(0.36,0.52)^{* * *}$ \\
\hline \multicolumn{2}{|c|}{ Age of onset of depression } & $0.26(0.20,0.33)^{* * *}$ & $0.27(0.19,0.36)^{* *}$ & $0.07(-0.02,0.17)$ & $-0.09(-0.07,0.05)$ \\
\hline \multirow[t]{2}{*}{ Sex } & Male & Ref & Ref & Ref & Ref \\
\hline & Female & $0.03(-0.91,0.99)$ & $0.53(-0.67,1.75)$ & $0.57(-0.75,1.90)$ & $0.28(-0.70,1.26)$ \\
\hline \multirow[t]{2}{*}{ Residency } & Urban & Ref & Ref & Ref & Ref \\
\hline & Rural & $1.02(-0.53,2.58)$ & $-0.16(2.13,1.80)$ & $0.903(-1.31,3.1)$ & $-0.98(-2.56,59)$ \\
\hline \multirow[t]{3}{*}{ Marital status } & Married & Ref & Ref & Ref & Ref \\
\hline & Single & $-0.31(-1.38,0.74)$ & $0.515(-0.81,1.8)$ & $1.15(-0.40,2.70)$ & $-0.84(1.96,0.27)$ \\
\hline & $\begin{array}{l}\text { Divorced/ } \\
\text { widowed }\end{array}$ & $-1.11(-2.35,0.12)$ & $-1.4(-3.18,0.2)$ & $-0.44(-2.15,1.26)$ & $-1.58(-2.8,0.3)$ \\
\hline \multirow[t]{2}{*}{ Perceived stigma } & No & Ref & Ref & Ref & Ref \\
\hline & Yes & $-2.38(-3.38,-1.3)^{* *}$ & $-1.02(-2.33,0.29)$ & $0.74(-0.82,2.31)$ & $0.38(-0.67,1.44)$ \\
\hline \multirow[t]{2}{*}{ Living with } & Families & Ref & Ref & Ref & Ref \\
\hline & Alone & $-1.92(-3.09,-0.74)^{*}$ & $0.41(-0.92,1.76)$ & $-1.27(-2.79,0.24)$ & $-0.52(-1.61,0.57)$ \\
\hline \multirow[t]{3}{*}{ Social support level } & Strong & Ref & Ref & Ref & Ref \\
\hline & Medium & $0.55(-0.42,1.52)$ & $-1.29(-2.74,0.14)$ & $-0.30(-2.07$ & $-0.25(-1.21$ \\
\hline & Poor & $-0.65(-1.71,0.41)$ & $-4.8(-6.4,-3.3)^{* * *}$ & $-3.78(-5.3,-2.2)^{* * *}$ & $-3.4(-4.6,-11.34)^{* * *}$ \\
\hline \multirow[t]{2}{*}{ Substance use } & No & Ref & Ref & Ref & Ref \\
\hline & Yes & $-1.19(-2.43,0.05)$ & $-0.11(-1.56,1.34)$ & $-1.29(-2.87,0.28)$ & $0.79(-0.38,1.96)$ \\
\hline \multirow{3}{*}{$\begin{array}{l}\text { Duration of } \\
\text { depression }\end{array}$} & $<5$ years & Ref & Ref & Ref & Ref \\
\hline & $5-10$ years & $0.02(-1.06,1.07)$ & $0.01(-1.32,1.34)$ & $-3.09(-4.61,1.59)^{*}$ & $-2.20(-3.41,-1.13)^{* * *}$ \\
\hline & $>10$ years & $-1.67(-2.9,-0.4)^{* * *}$ & $-0.73(-2.28,0.81)$ & $-0.46(-2.24,1.29)$ & $-0.58(-1.83,0.67)$ \\
\hline
\end{tabular}

Abbreviation: AMSH Amanuel Mental Specialized Hospital

${ }^{*} P<0.001,{ }^{* *} P<0.01,{ }^{* * *} P<0.05$

related to a better quality of life [15]. This might be due to the fact that living alone by itself can have more psychological distress and worsen the lowered self-image of people with depressive state [43].

In general, the findings of the current study recommends for professionals providing service for people with mental illness to improve the quality of life of people with depression by integrating the newly innovated positive mental health approach and psychosocial support together with the pharmacological treatment of depression. Health managers and policy makers are also expected to consider this issue in their plan, and appropriate resources should be allocated.

\section{Strength, limitations and generalisability of the study}

This study was conducted using standardized crossculturally validated tools to measure quality of life and other variables. Additionally, appropriate translation of the questionnaire and proper supervisition of the data collection were done. For the generalisability of the study, a probability sampling technique was used. However, the cross-sectional nature of the study design might not show the cause and effect relationship between variables and conducting further follow-up studies is highly recommended.

\section{Conclusion}

Nearly half of the study participants scored below the mean score of the WHOQOL-BRIEF quality of life for all the physical, psychological, social and environmental domains. Age of respondents, age of onset of depression, perceived stigma, living arrangement, social support level and duration of illness were statistically significant predictors of health related quality of life. This demonstrates a need for improving the quality of life of people with depression by integration of a positive mental 
health approach and bio-psychosocial view with the pharmacological treatments of depression. Moreover, strengthening social support, early identification and treatment of depression and prevention of stigma among individuals with depression is also highly recommended to improve the quality of life of people with depression.

\section{Abbreviations}

AMSH: Amanuel Mental Specialized Hospital; BD: Bipolar Disorder BSc: Bachelor of Science; Cl: Confidence Interval; CMD: Common Mental Disorder; CMHS: College Of Medicine and Health Science; DSM: Diagnostic and Statistical Manual of American Psychiatric Association; ETB: Ethiopian Birr; HRQOL: Health Related Quality Of Life; MDD: Major Depressive Disorder; MSc: Master of Science; OPD: Outpatient Department; OSSS: Oslo Social Support Scale; QOL: Quality Of Life; SD: Standard Deviation; SPSS: Statistical Package for Social Science; SQOL: Subjective Quality Of Life; WHOQOLBREF: World Health Organization Quality of Life Brief Version

\section{Acknowledgments}

Authors would like to acknowledge the University of Gondar and Amanuel Mental Specialized Hospital for the provision of ethical clearance. The authors would also like to thank the staffs of Amanuel Mental Specialized Hospital for their unreserved support in all stages this research work.

\section{Authors' contributions}

All authors participated in the conception, proposal writing, data analysis, drafting or revising the article, and gave final approval of this version to be published. All Authors agree to be equally accountable for all aspects of the work.

\section{Funding}

No specific fund was secured for this study.

\section{Availability of data and materials}

All the data included in the manuscript can be accessed from the corresponding author Seid Shumye upon request through the email address "seidshumye22@gmail.com".

\section{Ethics approval and consent to participate}

Ethical clearance was obtained from the Institutional Review Board (IRB) of University of Gondar. Written consent was obtained from each participant after delivering a brief explanation regarding the purpose and objectives of the study. All participants were informed as they have the right to refuse/ withdraw the interview at any time they want. The collected data were kept confidential and used only for the purpose of the study.

\section{Consent for publication}

Not applicable.

\section{Competing interests}

The authors declare that they have no competing interests.

\section{Received: 25 April 2019 Accepted: 15 October 2019}

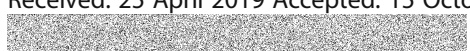

\section{References}

1. Group W. Development of the World Health Organization WHOQOL-BREF quality of life assessment. Psychol Med. 1998;28(3):551-8.

2. Quilty LC, Van Ameringen M, Mancini C, Oakman J, Farvolden P. Quality of life and the anxiety disorders. J Anxiety Disord. 2003;17(4):405-26.

3. Evans $\mathrm{S}$, Banerjee $\mathrm{S}$, Leese $\mathbf{M}$, Huxley P. The impact of mental illness on quality of life: a comparison of severe mental illness, common mental disorder and healthy population samples. Qual Life Res. 2007;16(1):17-29.

4. Papakostas GI, Petersen T, Mahal Y, Mischoulon D, Nierenberg AA, Fava M. Quality of life assessments in major depressive disorder: a review of the literature. Gen Hosp Psychiatry. 2004;26(1):13-7.

5. Michalak EE, Murray G, Young AH, Lam RW. Burden of bipolar depression. CNS Drugs. 2008;22(5):389-406.
6. Adewuya A, Makanjuola R. Subjective quality of life of Nigerian schizophrenia patients: sociodemographic and clinical correlates. Acta Psychiatr Scand. 2009;120(2):160-4.

7. ul Haq N, Ahmed N, Rasool G, Illyas M, Nasim A. Assessment of Health Related Quality of Life (Hrqol) of Patients with Severe Mental Illness Attending Tertiary Care Public Hospitals of Quetta, Pakistan. Value Health. 2016;19(7):A843.

8. Depression W. Other common mental disorders: global health estimates. Geneva: World Health Organization; 2017. p. 1-24.

9. Hailemariam S, Tessema F, Asefa M, Tadesse H, Tenkolu G. The prevalence of depression and associated factors in Ethiopia: findings from the National Health Survey. Int J Ment Heal Syst. 2012;6(1):23.

10. Bonicatto S, Dew M, Zaratiegui R, Lorenzo L, Pecina P. Adult outpatients with depression: worse quality of life than in other chronic medical diseases in Argentina. Soc Sci Med. 2001;52(6):911-9.

11. Chung L, Pan A-W, Hsiung P-C. Quality of life for patients with major depression in Taiwan: a model-based study of predictive factors. Psychiatry Res. 2009;168(2):153-62.

12. Chan SW, Hsiung PC, Thompson DR, Chen SC, Hwu HG. Health-related quality of life of Chinese people with schizophrenia in Hong Kong and Taipei: a cross-sectional analysis. Res Nurs Health. 2007;30(3):261-9.

13. Awadalla A, Ohaeri J, Salih A, Tawfiq A. Subjective quality of life of community living Sudanese psychiatric patients: comparison with family caregivers' impressions and control group. Qual Life Res. 2005;14(8): 1855-67.

14. Rayan A, Mahroum MH. The correlates of quality of life among Jordanian patients with major depressive disorder. Res Psychol Behav Sci. 2016;4(2): 28-33.

15. Priebe S, Reininghaus U, McCabe R, Burns T, Eklund M, Hansson L, et al. Factors influencing subjective quality of life in patients with schizophrenia and other mental disorders: a pooled analysis. Schizophr Res. 2010;121(1-3): 251-8.

16. Skevington SM, McCrate FM. Expecting a good quality of life in health: assessing people with diverse diseases and conditions using the WHOQOLBREF. Health Expect. 2012;15(1):49-62

17. Cui R. Editorial: a systematic review of depression. Curr Neuropharmacol. 2015;13(4):480.

18. Farah WH, Alsawas M, Mainou M, Alahdab F, Farah MH, Ahmed AT, et al. Non-pharmacological treatment of depression: a systematic review and evidence map. Evid Based Med. 2016;21(6):214-21.

19. Okuyama T, Akechi T, Mackenzie L, Furukawa TA. Psychotherapy for depression among advanced, incurable cancer patients: a systematic review and meta-analysis. Cancer Treat Rev. 2017;56:16-27 Anxiety Depression Neoplasms Palliative care Psycho-oncology Psychotherapy.

20. Yang L, Zhao Y, Wang Y, Liu L, Zhang X, Li B, et al. The effects of psychological stress on depression. Curr Neuropharmacol. 2015;13(4): 494-504.

21. Girard JM, Cohn JF, Mahoor MH, Mavadati SM, Hammal Z, Rosenwald DP. Nonverbal social withdrawal in depression: evidence from manual and automatic analysis. Image Vis Comput. 2014;32(10):641-7 Depression Facs Facial Expression Head Motion Multimodal.

22. Bech P, Carrozzino D, Austin SF, Moller SB, Vassend O. Measuring euthymia within the neuroticism scale from the NEO personality inventory: a Mokken analysis of the Norwegian general population study for scalability. J Affect Disord. 2016;193:99-102 Dysthymia Euthymia Mokken analysis NEO Personality Inventory.

23. Carrozzino D, Svicher A, Patierno C, Berrocal C, Cosci F. The euthymia scale: a clinimetric analysis. Psychother Psychosom. 2019;88(2):119-21.

24. Sherbourne CD, Edelen MO, Zhou A, Bird C, Duan N, Wells KB. How a therapy-based quality improvement intervention for depression affected life events and psychological well-being over time: a 9-year longitudinal analysis. Med Care. 2008:46(1):78-84.

25. Fava GA, Carrozzino D, Lindberg L, Tomba E. The clinimetric approach to psychological assessment: a tribute to per Bech, MD (1942-2018). Psychother Psychosom. 2018;87(6):321-6.

26. Carrozzino D. Clinimetric approach to rating scales for the assessment of apathy in Parkinson's disease: a systematic review. Prog Neuropsychopharmacol Biol Psychiatry. 2019;94(109641):3 Apathy Clinimetric approach Parkinson's disease Rating scales Systematic review.

27. Sarris J O'Neil A Coulson CE, Schweitzer I, Berk M. Lifestyle medicine for depression. BMC Psychiatry. 2014;14(107):14-107. 
28. Bekele YY, Flisher AJ, Alem A, Baheretebeb Y. Pathways to psychiatric care in Ethiopia. Psychol Med. 2009;39(3):475-83.

29. Skevington SM, Lotfy M, O'Connell KA. The World Health Organization's WHOQOL-BREF quality of life assessment: psychometric properties and results of the international field trial. A report from the WHOQOL group. Qual Life Res. 2004;13(2):299-310.

30. Tesfaye M, Olsen MF, Medhin G, Friis H, Hanlon C, Holm L. Adaptation and validation of the short version WHOQOL-HIV in Ethiopia. Int J Ment Health Syst. 2016;10(29):016-0062 Cross-cultural validation Ethiopia Hiv Quality of life WHOQOL-HIV bref.

31. Group TW. The World Health Organization Quality of Life Assessment (WHOQOL): development and general psychometric properties. Soc Sci Med. 1998:46(12):1569-85.

32. Shumaker SC, Frazier SK, Moser DK, Chung ML. Psychometric properties of the multidimensional scale of perceived social support in patients with heart failure. J Nurs Meas. 2017;25(1):90-102.

33. Beyhaghi H, Reeve BB, Rodgers JE, Stearns SC. Psychometric Properties of the Four-Item Morisky Green Levine Medication Adherence Scale among Atherosclerosis Risk in Communities (ARIC) Study Participants. Value Health. 2016;19(8):996-1001 *causal indicator *effect indicator *factorial validity *medication adherence *reliability.

34. Jacoby A. Epilepsy and stigma: an update and critical review. Curr Neurol Neurosci Rep. 2008;8(4):339-44.

35. Trevizan FB, Miyazaki M, Silva YLW, Roque CMW. Quality of life, depression, anxiety and coping strategies after heart transplantation. Braz J Cardiovasc Surg. 2017;32(3):162-70.

36. Peltzer K, Phaswana-Mafuya N. Depression and associated factors in older adults in South Africa. Glob Health Action. 2013;6:1-9 South AfricaWho sage older adults risk factors self-reported depression symptoms.

37. Kuehner C, Buerger C. Determinants of subjective quality of life in depressed patients: the role of self-esteem, response styles, and social support. J Affect Disord. 2005;86(2-3):205-13.

38. Zeng $Q, X u$ Y, Chun WW. Quality of life in outpatients with depression in China. J Affect Disord. 2013;150(2):513-21 Antidepressant First-visit patients Outpatients with depression Quality of life.

39. Olusina AK, Ohaeri JU. Subjective quality of life of recently discharged Nigerian psychiatric patients. Soc Psychiatry Psychiatr Epidemiol. 2003; 38(12):707-14

40. Heider D, Angermeyer MC, Winkler I, Schomerus G, Bebbington PE, Brugha T, et al. A prospective study of quality of life in schizophrenia in three European countries. Schizophr Res. 2007;93(1-3):194-202.

41. Xiang YT, Hou YZ, Yan F, Dixon LB, Ungvari GS, Dickerson F, et al. Quality of life in community-dwelling patients with schizophrenia in China. J Nerv Ment Dis. 2012;200(7):584-7.

42. Holubova M, Prasko J, Ociskova M, Marackova M, Grambal A, Slepecky M. Self-stigma and quality of life in patients with depressive disorder: a crosssectional study. Neuropsychiatr Dis Treat. 2016;12:2677-87 Depressive disorder quality of life self-stigma.

43. Hsiung PC, Pan AW, Liu SK, Chen SC, Peng SY, Chung L. Mastery and stigma in predicting the subjective quality of life of patients with schizophrenia in Taiwan. J Nerv Ment Dis. 2010;198(7):494-500.

44. Ribas AC, Lam CS. Social support and quality of life among Latinos with mental illness. J Nerv Ment Dis. 2010;198(2):137-43.

\section{Publisher's Note}

Springer Nature remains neutral with regard to jurisdictional claims in published maps and institutional affiliations.

Ready to submit your research? Choose BMC and benefit from:
- fast, convenient online submission
- thorough peer review by experienced researchers in your field
- rapid publication on acceptance
- support for research data, including large and complex data types
- gold Open Access which fosters wider collaboration and increased citations
- maximum visibility for your research: over 100M website views per year
At BMC, research is always in progress.
Learn more biomedcentral.com/submissions

